\title{
The tar reduction study: randomised trial of the effect of cigarette tar yield reduction on compensatory smoking
}

Christopher Frost*, Frances M Fullerton, Alison M Stephen, Rossana Stone, Ans Nicolaides-Bouman, James Densem, Nicholas J Wald, Adrian Semmence

\begin{abstract}
Background - Observational and short term intervention studies have reported that smokers of low tar cigarettes inhale more deeply (that is, compensate) than those who smoke high tar cigarettes. To quantify this effect a long term randomised trial was conducted on the effects of switching to low tar cigarettes.

Methods - The trial was carried out between April 1985 and March 1988 among cigarette smokers in the British Civil Service, measuring blood carboxyhaemoglobin (COHb) levels and serum cotinine levels as markers of tobacco smoke intake. Volunteers first switched to a cigarette brand yielding around $10 \%$ less tar than their usual brand to identify smokers able to change brand. The 434 subjects who successfully switched were then randomly allocated to one of three groups: (a) "fast reduction" group which changed to a brand of cigarettes with a tar yield of about half that of their usual brand; (b) "slow reduction" group which reduced to the same level in steps over several months; and (c) a control group which continued smoking cigarettes with a tar yield $10 \%$ lower than their usual brand.
\end{abstract}

Results - Over the course of the trial cigarette consumption declined slightly in all three groups. In both the "fast reduction" and the "slow reduction" groups, intake of $\mathrm{COHb}$ and cotinine was reduced, though not to the same extent as the yield reduction. Comparison of the results before randomisation with those at the end of the trial showed that a reduction in carbon monoxide yield of $45 \%$ was associated with a decrease in carbon monoxide intake of $19 \%(95 \%$ confidence interval $14 \%$ to $24 \%$ ) and that a reduction in nicotine yield of $40 \%$ was associated with an $11 \%(6 \%$ to $16 \%)$ reduction in nicotine intake, reflecting relative intakes of about 1.5 for both carbon monoxide and nicotine in the "fast reduction" group. Results were similar in the "slow reduction" group with a $42 \%$ reduction in carbon monoxide yield, a $16 \%(11 \%$ to $22 \%)$ reduction in carbon monoxide intake, a $37 \%$ reduction in nicotine yield, and a $6 \%(0 \%$ to $13 \%)$ reduction in nicotine intake. Estimates of compensation derived from these results were
$65 \%$ for carbon monoxide, $79 \%$ for nicotine, and $62 \%$ for tar.

Conclusions - Compensation, demonstrated when switching from a high tar cigarette to a low tar one, was incomplete. Advising people who have failed to give up smoking to switch to low tar cigarettes will reduce the intake of smoke constituents to a small extent. This would be expected to decrease their risk of smoking-related diseases, although by a smaller amount than would be achieved by giving up smoking altogether.

(Thorax 1995;50:1038-1043)

Keywords: smoking, low yield, compensation, tar.

When smokers switch to lower tar yield cigarettes it is possible that they will inhale more smoke to compensate for the reduction in strength of the tobacco smoke. This effect is referred to as "compensation" by the International Agency for Research on Cancer (IARC) which summarised the studies of this effect. ${ }^{1}$ Studies on compensation published since the IARC report do not materially alter the conclusions of the report. The studies reviewed fall into two categories: short term experimental studies in which biochemical markers of tobacco smoke were measured in the same individuals before and after switching from one type of cigarette to another, and observational cross sectional studies which compare marker levels among smokers of cigarettes with different tar yields. Studies of both types showed that substantial compensation occurs. However, because of their design, the interpretation of results from these studies must be cautious. It is possible that people who switch to a lower tar yield cigarette smoke in a systematically different manner from those who do not switch, thus introducing bias into the observational studies. The experimental studies may be too short to reflect "normal" switching, and neither type of study may be applicable to long term switching. To reduce the possibility of such biases, a large randomised trial of switching to low tar cigarettes was conducted. The size and design of this study allowed quantification of the extent of compensation.

\section{Methods}

A total of 33800 British civil servants (men and women) employed at the Department of 
Table 1 Mean and standard deviations of marker levels, yields, and number of cigarettes smoked by group and visit

\begin{tabular}{|c|c|c|c|c|c|c|c|c|c|c|c|c|c|c|c|c|}
\hline \multirow[b]{3}{*}{ No. of individuals } & \multicolumn{5}{|c|}{ Control group } & \multicolumn{5}{|c|}{ Fast reduction group } & \multicolumn{5}{|c|}{ Slow reduction group } & \multirow{2}{*}{$\begin{array}{l}\text { Median standard } \\
\text { deviation across } \\
\text { the } 15 \text { group visits }\end{array}$} \\
\hline & $\begin{array}{l}\text { Visit } \\
1 \\
\text { (Pre- } \\
\text { random }\end{array}$ & $\begin{array}{l}2 \\
\text { nisation) }\end{array}$ & $\begin{array}{l}3 \\
\text { (Post- } \\
\text { random }\end{array}$ & $\begin{array}{l}4 \\
\text { nisation) }\end{array}$ & 5 & $\begin{array}{l}\text { Visit } \\
1 \\
\text { (Pre- } \\
\text { randon }\end{array}$ & $\begin{array}{l}2 \\
\text { nisation) }\end{array}$ & $\begin{array}{l}3 \\
\text { (Post- } \\
\text { random }\end{array}$ & $\begin{array}{l}4 \\
\text { nisation }\end{array}$ & 5 & $\begin{array}{l}\text { Visit } \\
1 \\
\text { (Pre- } \\
\text { randon }\end{array}$ & $\begin{array}{l}2 \\
\text { misation) }\end{array}$ & $\begin{array}{l}3 \\
\text { (Post- } \\
\text { random }\end{array}$ & $\begin{array}{l}4 \\
\text { nisation }\end{array}$ & 5 & \\
\hline & 144 & 144 & 133 & 127 & 122 & 145 & 145 & 120 & 107 & 99 & 145 & 145 & 127 & 113 & 105 & - \\
\hline Tar yield (mg) & $15 \cdot 5$ & $14 \cdot 1$ & $14 \cdot 0$ & $14 \cdot 0$ & $14 \cdot 1$ & $15 \cdot 5$ & $14 \cdot 0$ & $7 \cdot 9$ & $7 \cdot 9$ & $7 \cdot 8$ & $15 \cdot 5$ & $14 \cdot 1$ & $12 \cdot 1$ & $9 \cdot 7$ & 8 & $1 \cdot 4$ \\
\hline CO yield (mg) & $15 \cdot 7$ & $14 \cdot 4$ & $14 \cdot 4$ & $14 \cdot 4$ & $14 \cdot 4$ & $15 \cdot 7$ & 14.5 & $8 \cdot 5$ & 8.5 & $8 \cdot 4$ & $15 \cdot 7$ & 14.5 & 13.5 & $10 \cdot 3$ & $8 \cdot 8$ & 1.8 \\
\hline $\mathrm{COHb}(\%)$ & $4 \cdot 73$ & $4 \cdot 76$ & $4 \cdot 51$ & 4.35 & 4.52 & $4 \cdot 74$ & 4.95 & $4 \cdot 06$ & 3.85 & 3.93 & $4 \cdot 56$ & $4 \cdot 70$ & $4 \cdot 17$ & 3.80 & $3 \cdot 85$ & $2 \cdot 10$ \\
\hline Nicotine yield (mg) & $1 \cdot 38$ & 1.31 & 1.32 & $1 \cdot 31$ & $1 \cdot 31$ & $1 \cdot 38$ & $1 \cdot 32$ & 0.83 & 0.82 & $0 \cdot 81$ & 1.35 & $1 \cdot 31$ & $1 \cdot 24$ & 0.98 & 0.84 & $0 \cdot 12$ \\
\hline Cotinine $(\mathrm{ng} / \mathrm{ml})$ & 293 & 283 & 286 & 274 & 285 & 300 & 305 & 277 & 262 & 269 & 289 & 289 & 281 & 269 & 271 & 135 \\
\hline Today's cigarettes $(n)$ & $6 \cdot 3$ & $6 \cdot 1$ & $5 \cdot 5$ & $5 \cdot 3$ & $5 \cdot 2$ & $7 \cdot 0$ & $6 \cdot 4$ & $5 \cdot 7$ & $5 \cdot 8$ & $5 \cdot 9$ & $6 \cdot 4$ & $5 \cdot 9$ & $5 \cdot 6$ & $5 \cdot 7$ & $5 \cdot 6$ & $3 \cdot 9$ \\
\hline Yesterday's cigarettes (n) & $19 \cdot 3$ & $18 \cdot 4$ & $17 \cdot 1$ & $16 \cdot 3$ & $16 \cdot \overline{4}$ & $21 \cdot 3$ & $19 \cdot 2$ & $18 \cdot 8$ & $18 \cdot 3$ & $18 \cdot 4$ & $20 \cdot 0$ & $18 \cdot 8$ & $17 \cdot 8$ & $18 \cdot 3$ & 18.5 & $7 \cdot 6$ \\
\hline
\end{tabular}

$\mathrm{CO}=$ carbon monoxide; $\mathrm{COHb}=$ carboxyhaemoglobin.

the Environment, Home Office, and Ministry of Defence in London, the Departments of Health and Social Security in Newcastle and Blackpool, Customs and Excise in Southend, Bonds and Stocks in Lytham St Annes, the National Savings Bank in Glasgow, the Inland Revenue in East Kilbride, and the Manpower Services Commission in Sheffield were sent questionnaires asking for details of their smoking habits with a view to participating in a trial of switching to low tar cigarettes. Of those who replied, 882 smoked relatively high tar yield cigarettes (more than $16 \mathrm{mg}$, or $14 \mathrm{mg}$ in the latter period of the study after changes in tar tables). Of these, 603 agreed to join the trial at site visits by study organisers between April 1985 and July 1987 . All volunteers were asked to switch to cigarettes with a tar yield that was about $10 \%$ lower than their usual brand for two months to identify those who were willing and able to change cigarette brand. At the end of this period the volunteers were interviewed again. At this second visit 434 individuals had successfully changed to a different brand of cigarettes and were willing to continue for a further three visits at two monthly intervals. The subjects were randomly allocated into three groups: (a) a group that changed in one step to a brand of cigarettes with a tar yield about half that of their usual brand (the fast reduction group); (b) a group that reduced to the same level in steps over several months (the slow reduction group); and (c) a control group that continued to smoke the brand with a tar yield about $10 \%$ lower than their usual brand. Each subject was asked to return on three further occasions at two monthly intervals (table 1). At each of the five visits each subject completed a questionnaire about smoking habits over the previous 48 hours, venous blood was taken and the concentration of carbon monoxide in the breath was measured. At each visit they were given a single pack of 20 cigarettes of the type that they were requested to smoke.

Volunteers were allowed to choose their own brand within a given range of tar yield. To assess compliance with the study protocol, volunteers were asked to save their cigarette packet tops. The extent of compensation was estimated by measuring carboxyhaemoglobin $(\mathrm{COHb})$ and serum cotinine levels. $\mathrm{COHb}$ is a marker of carbon monoxide intake, with a half life of approximately two hours. ${ }^{2}$ Cotinine is a metabolite of nicotine with a half life of around 24 hours. ${ }^{3}$ The COHb levels were measured within 36 hours of the blood sample being taken using a CO-oximeter (Model IL-282, Instrumentation Laboratory UK Ltd). Serum cotinine concentration was measured by radioimmunoassay. ${ }^{4}$

QUANTIFYING THE EXTENT OF COMPENSATION

Two measures, both previously defined, ${ }^{15}$ were used to quantify compensation.

\section{(i) Relative intake}

Relative intake is the proportional change in the biochemical marker on switching to a new brand of cigarette (the marker providing a measure of intake) divided by the proportional change in yield:

$$
\text { Relative intake }=\frac{\text { marker }_{2} / \text { marker }_{1}}{\text { yield }_{2} / \text { yield }_{1}}
$$

Relative intake measures strength of inhaling. It is 1 when a change in yield produces the same proportional change in marker (no compensation), and it is greater than unity when the reduction in yield is proportionally larger than the reduction in the marker level (compensation).

Relative intake will vary in magnitude according to the change in yield of a particular smoke constituent. With a small reduction in yield (say 5\%), relative intake would be small even if compensation is complete $(1.06=$ $1 / 0 \cdot 95)$. With a large reduction in yield (say $90 \%$ ), relative intake will be large even if compensation is slight (say $80 \%$ rather than $90 \%$ reduction in marker levels) $(2=0 \cdot 2 / 0 \cdot 1$ in this example).

\section{(ii) Compensation}

The summary figure for compensation need not depend on the reduction in yield. It measures the degree to which proportional changes in a smoker's intake of a particular smoke constituent falls short of the same proportional changes in the yield of that constituent. by:

Compensation (C) is defined as previously ${ }^{5}$

$$
1-\mathrm{C}=\frac{\log \left(\text { marker }_{2}\right)-\log \left(\text { marker }_{1}\right)}{\log \left(\text { yield }_{2}\right)-\log \left(\text { yield }_{1}\right)}
$$

where marker $_{1}$ and yield ${ }_{1}$ are the levels of marker and yield before the brand change, and 
marker $_{2}$ and yield ${ }_{2}$ are their levels afterwards. A logarithmic model is appropriate here because proportional changes in yield are being related to proportional changes in marker.

When changing cigarette brand the proportional change of one constituent is different from that of another: the ratio of the two yields (yield ${ }_{2} /$ yield $_{1}$ ) will vary. Relative intake is likely to be similar for each constituent. It will vary only to the extent that the proportion of carbon monoxide, nicotine, and tar in tobacco smoke may vary according to the intensity of inhaling. From equations (1) and (2) it follows that the relationship between relative intake (RI) and compensation $(\mathrm{C})$ for a specific brand change is as follows:

$$
\log (\mathrm{RI})=-\mathrm{C} \times \log \left(\text { yield }_{2} / \text { yield }_{1}\right)
$$

This formula shows that the same values of relative intake for each constituent will lead to different values of compensation if the proportional reductions in yields are different. It follows that no conclusion can be drawn from values of compensation (which only summarise the relationship between marker and yield levels) about which smoke constituents are "driving compensation". Conclusions about which smoke constituents are "driving compensation" can only be drawn by comparing relative intakes for the different smoke constituents for a particular brand change.

If relative intake for a particular brand change is assumed constant for all smoke constituents, the above formula can be used to calculate compensation for tar (for which no marker of intake is available).

\section{STATISTICAL METHODS}

Mean levels of cotinine and $\mathrm{COHb}$ were calculated at each visit in the three groups. Confidence intervals on the reductions in marker levels between the final visit and the average of the two prerandomisation visits were estimated using standard errors derived from a within person analysis of changes in marker levels and, for simplicity, applied to differences in the group means.

Relative intake for each group and for each smoke constituent at each of the post-randomisation visits was calculated by relating the average yield and marker levels at the two prerandomisation visits to the average yield and marker levels at each of the three postrandomisation visits.

Compensation at each of the three postrandomisation visits was then calculated by relating yield and marker levels at these visits to the average of the two baseline levels. Compensation in each group of individuals at each visit was estimated by plotting log ( marker $_{2} /$ marker $_{1}$ ) against $\log \left(\right.$ yield $_{2} /$ yield $_{1}$ ) and compensation was estimated by regressing log $\left(\right.$ marker $_{2} /$ marker $\left._{1}\right)$ on $\log \left(\right.$ yield $_{2} /$ yield $\left._{1}\right)$ constraining the regression line to pass through the origin. The slope of the regression line estimates the average change in log (marker) for a unit change in log (yield) and is therefore an estimate of $1-C$. The regression analysis allows a confidence interval for compensation to be calculated.

$\mathrm{COHb}$ and cotinine levels depend on the number of cigarettes smoked in the period prior to blood being taken. There was a slight decline in the average number of cigarettes smoked by participants in all three groups over the course of the study, probably because the participants were a group motivated to reduce the extent of their smoking. To assess the effect of low tar cigarettes it is necessary to standardise estimates of compensation to allow for changes in the number of cigarettes smoked in the period prior to each visit.

Compensation for cotinine was adjusted for cigarette consumption on both the day of visit and the day before the visit because the half life of cotinine is sufficiently large (about one day $)^{3}$ for consumption on both days to influence cotinine levels. The estimate of compensation was adjusted by carrying out a multiple regression (constrained to pass through the origin) of $\log \left(\right.$ marker $_{2} /$ marker $\left._{1}\right)$ on $\left.\log \left(\text { yield }{ }_{2} / \text { yield }\right)_{1}\right), \log \left(\mathrm{t}_{2} / \mathrm{t}_{1}\right)$ and $\log \left(\mathrm{p}_{2} / \mathrm{p}_{1}\right)$ where $t_{2}$ and $p_{2}$ are the number of cigarettes smoked on the day of the visit and the day before the visit, respectively, and $t_{1}$ and $p_{1}$ are the equivalent baseline values. The partial regression coefficient for $\log \left(\right.$ yield $_{2} /$ yield $_{1}$ ) is an estimate of $1-C$ adjusted for the number of cigarettes smoked in the period prior to the visit.

$\mathrm{COHb}$, with a half life of only about two hours $^{2}$ for a moderately sedentary individual, is influenced by cigarette consumption only on the day of the visit. The times at which cigarettes were smoked on the day of the visit will also have a strong influence on $\mathrm{COHb}$ levels. Participants in the study attended at different times at different visits. To allow for this varying influence, a cigarette smoked immediately before the visit was counted as one cigarette, one smoked two hours previously counted as one half of a cigarette, one smoked four hours previously counted as a quarter of a cigarette, etc. Plotting log $\mathrm{COHb}$ against log (cigarettes adjusted for half life) for each group at each visit revealed a satisfactory straight line relationship. Compensation for $\mathrm{COHb}$ was adjusted for consumption by carrying out a multiple regression of $\log \left(\right.$ marker $_{2} /$ marker $\left._{1}\right)$ on $\log \left(\right.$ yield $_{2} /$ yield $\left._{1}\right)$ and $\log \left(a_{2} / a_{1}\right)$ where $a_{2}$ is the number of cigarettes adjusted for half life smoked on the day of the visit and $a_{1}$ the equivalent baseline values. The exact half life of $\mathrm{COHb}$ varies according to activity level. ${ }^{2}$ Adjustments assuming a half life of three hours and four hours were also carried out. The correlation between $\log \mathrm{COHb}$ and $\log$ (cigarettes adjusted for half life) for each group at each visit was slightly higher using an assumed half life of two hours, so this was adopted in the compensation adjustment.

In view of the half lives of $\mathrm{COHb}$ and cotinine, we excluded from the cotinine analysis data relating to person visits where either no cigarettes were smoked on the day seen or on the day before, and in the $\mathrm{COHb}$ analysis data relating to person visits where less than 0.3 of an adjusted (for half life of $\mathrm{COHb}$ ) cigarette 


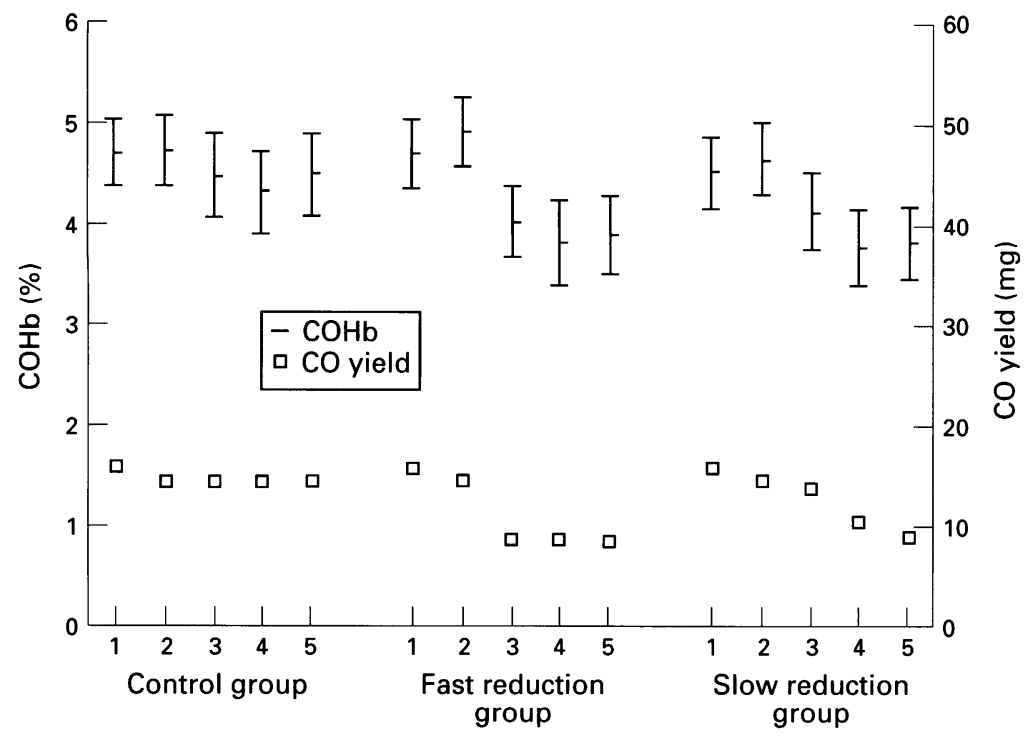

Figure 1 Mean blood levels (with 95\% confidence intervals) of carboxyhaemoglobin $(\mathrm{COHb})$ related to carbon monoxide yield according to randomisation group and visit.

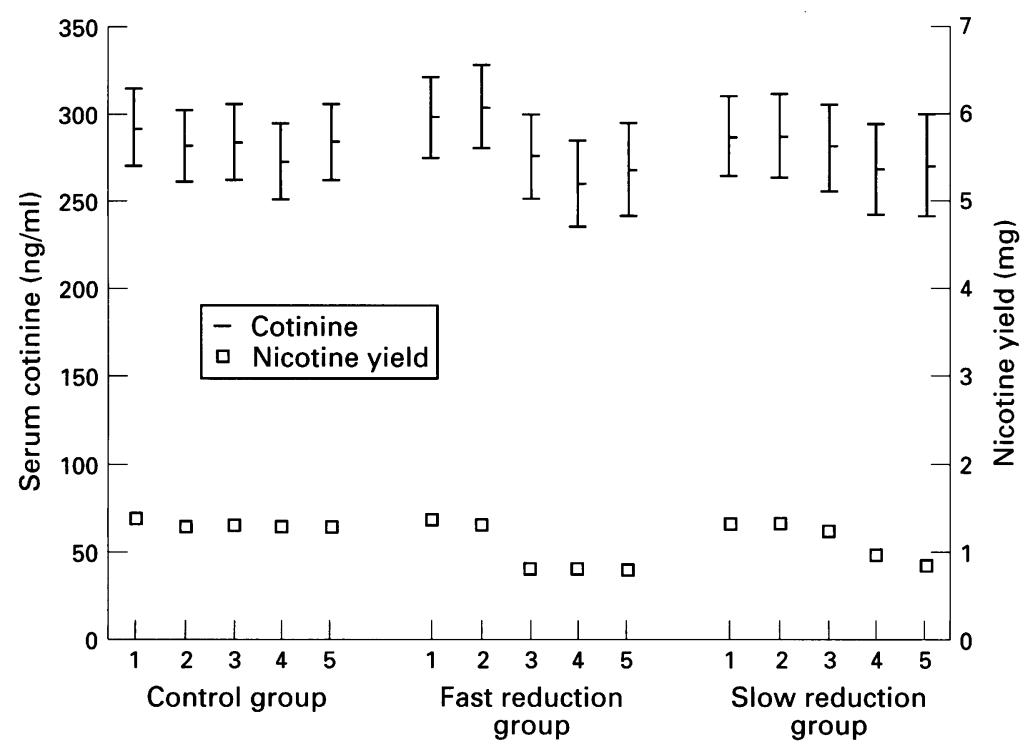

Figure 2 Mean blood levels (with 95\% confidence intervals) of cotinine related to nicotine yield according to randomisation group and visit.

was smoked on the day seen. Data from one individual who reported smoking more than 70 cigarettes a day immediately prior to one visit were also excluded from all analyses.

\section{Results}

Of the total of 434 subjects, 326 attended all three post-randomisation visits. A further 54 attended at least one post-randomisation visit and 54 attended none. Among the 108 subjects who did not attend the final visit, $20(18 \%)$ were known to have given up smoking (confirmed in 18 by measuring cotinine levels in urine and in the other two by measuring breath carbon monoxide). No subject who did attend had given up smoking. Compliance with the study protocol was generally good in all groups; at all visits over $80 \%$ of the packet tops collected were of the tar yield of the brand that the participants had been asked to smoke.

Table 1 shows the mean tar, carbon monoxide, and nicotine yields of the brand of cigarette most commonly smoked by each of the subjects (ascertained from the collection of packet tops) at each visit in the three groups. Marker levels and cigarette consumption together with typical standard deviations are also given. The reductions in both cotinine and $\mathrm{COHb}$ levels across the five visits in the two intervention groups, although relatively small, were statistically significant. In the fast reduction group, comparing visit 5 with the mean of two prerandomisation visits, the reductions were $19 \%$ ( $95 \%$ confidence interval (CI) $14 \%$ to $24 \%$ ) in $\mathrm{COHb}$ and $11 \%$ (6\% to $16 \%)$ in cotinine. In the slow reduction group the reductions were $16 \%(11 \%$ to $22 \%)$ and $6 \%$ ( $0 \%$ to $13 \%)$, respectively. A statistically significant reduction in the number of cigarettes smoked on the day before the visit was also observed.

Figures 1 and 2 relate the mean $\mathrm{COHb}$ and cotinine levels to carbon monoxide and nicotine yields according to randomisation group and visit. They show a decrease (mainly between visits 2 and 3) in the fast reduction group and a more gradual decrease in the slow reduction group. These results show that, when switching to lower tar cigarettes, intake of carbon monoxide (as shown by $\mathrm{COHb}$ levels) and intake of nicotine (as shown by cotinine levels) are reduced. The fact that the reductions in the marker levels are proportionally smaller than the reduction in the yields indicates that compensation has occurred. Marker levels at visit 5 were similar in the two intervention arms of the trial, indicating that there was little, if any, difference according to how quickly the switch

Table 2 Compensation and relative intake by visit

\begin{tabular}{|c|c|c|c|c|c|c|c|c|c|}
\hline & \multicolumn{4}{|c|}{ Fast reduction group } & \multicolumn{4}{|c|}{ Slow reduction group } & \multirow{2}{*}{$\begin{array}{l}\text { All groups combined } \\
\text { Visit } \\
5\end{array}$} \\
\hline & $\begin{array}{l}\text { Visit } \\
1 / 2\end{array}$ & 3 & 4 & 5 & $\begin{array}{l}\text { Visit } \\
1 / 2\end{array}$ & 3 & 4 & 5 & \\
\hline \multicolumn{10}{|l|}{ Carbon monoxide: } \\
\hline & $1 \cdot 00$ & 0.56 & 0.56 & 0.55 & $1 \cdot 00$ & 0.89 & 0.68 & 0.58 & - \\
\hline Marker* & $1 \cdot 00$ & 0.84 & 0.79 & 0.81 & $1 \cdot 00$ & 0.90 & 0.83 & 0.84 & - \\
\hline Relative intake & - & $\begin{array}{l}1.49 \\
68.3\end{array}$ & $\begin{array}{l}1.42 \\
57.5\end{array}$ & $\begin{array}{l}1.46 \\
65.9\end{array}$ & - & $9 \cdot 01$ & $\begin{array}{l}1.21 \\
57.7\end{array}$ & $\begin{array}{l}1.43 \\
63.8\end{array}$ & \\
\hline $\begin{array}{l}\text { Compensation }(\%) \\
(95 \% \text { confidence interva }\end{array}$ & & $\begin{array}{l}68 \cdot 3 \\
(58 \cdot 8 \text { to } 77 \cdot 7)\end{array}$ & $\begin{array}{l}51.5 \\
(46.5 \text { to } 68.4)\end{array}$ & $\begin{array}{l}65 \cdot 9 \\
(56 \cdot 8 \text { to } 75 \cdot 1)\end{array}$ & & $\begin{array}{l}92 \cdot 5 \\
(70 \cdot 8 \text { to } 114 \cdot 2)\end{array}$ & $(40 \cdot 7$ to $74 \cdot 7)$ & $\begin{array}{l}63 \cdot 8 \\
(52 \cdot 0 \text { to } 75 \cdot 6)\end{array}$ & $\begin{array}{l}65 \cdot 4 \\
(58 \cdot 4 \text { to } 72 \cdot 4)\end{array}$ \\
\hline \multicolumn{10}{|l|}{ Nicotine: } \\
\hline Yield* ${ }^{*}$ & $1 \cdot 00$ & 0.61 & 0.61 & $0 \cdot 60$ & $1 \cdot 00$ & 0.93 & 0.74 & 0.63 & - \\
\hline Marker* & 1.00 & 0.92 & 0.87 & 0.89 & 1.00 & 0.98 & 0.93 & 0.94 & - \\
\hline Relative intake & - & $1 \cdot 49$ & $1 \cdot 43$ & $1 \cdot 48$ & - & $1 \cdot 04$ & 1.26 & 1.49 & - \\
\hline $\begin{array}{l}\text { Compensation (\%) } \\
\text { (95\% confidence interva }\end{array}$ & - & $\begin{array}{l}78 \cdot 3 \\
(70 \cdot 0 \text { to } 86 \cdot 7)\end{array}$ & $\begin{array}{l}76.5 \\
(65.5 \text { to } 87.5)\end{array}$ & $\begin{array}{l}81 \cdot 3 \\
(72 \cdot 3 \text { to } 90 \cdot 2)\end{array}$ & - & $\begin{array}{l}94.4 \\
(63.4 \text { to } 125.5)\end{array}$ & $\begin{array}{l}74 \cdot 3 \\
(58.9 \text { to } 89 \cdot 7)\end{array}$ & $\begin{array}{l}77 \cdot 7 \\
(65.4 \text { to } 89.9)\end{array}$ & $\begin{array}{l}78 \cdot 8 \\
(70 \cdot 4 \text { to } 87 \cdot 3)\end{array}$ \\
\hline
\end{tabular}

${ }^{*}$ Mean levels as a proportion of mean levels prerandomisation. 
Table 3 Predicted relative intakes and intake reductions for a range of reductions in yield

\begin{tabular}{llll}
\hline & $\begin{array}{l}\text { Reduction } \\
\text { in yield } \\
(\%)\end{array}$ & $\begin{array}{l}\text { Estimated } \\
\text { relative } \\
\text { intake }\end{array}$ & $\begin{array}{l}\text { Estimated } \\
\text { reduction in } \\
\text { intake (\%) }\end{array}$ \\
\hline \multirow{3}{*}{ Tar } & 25 & 1.20 & 10 \\
& 50 & 1.54 & 23 \\
Carbon monoxide & 75 & 2.36 & 41 \\
& 25 & 1.21 & 9 \\
Nicotine & 50 & 1.57 & 21 \\
& 25 & 2.48 & 38 \\
& 50 & 1.25 & 6 \\
& 75 & 1.73 & 14 \\
& & 2.98 & 25 \\
\hline
\end{tabular}

to lower tar brands was accomplished. There was also a slight reduction in both carbon monoxide and cotinine levels in the control group, probably due to the reduction in the number of cigarettes smoked in this group (table 1).

Table 2 shows estimates of relative intake and compensation for each smoke constituent at each of the post-randomisation visits. In the fast reduction group, relative intake was similar at each of the three visits for both nicotine and carbon monoxide (always in the range $1 \cdot 4-1 \cdot 5$ ). In the slow reduction group, as expected, relative intake increased from visit to visit because of the stepwise reductions in yield. At the final visit relative intake for both carbon monoxide $(1.43)$ and nicotine $(1.49)$ were comparable with the values of relative intake in the fast reduction group. The relative intakes, whether calculated from carbon monoxide or nicotine, show that at visit 5 smokers were smoking their cigarettes $50 \%$ more intensively. Comparison of the values for compensation across groups and visits shows that there is little evidence to suggest that compensation varies with visit or by group. Only in the slow reduction group at visit 3, where a very small reduction in yield was achieved (and confidence intervals are wide), did compensation appear to be somewhat higher than at other times. At visit 5 the estimates of compensation in the two groups were almost identical. A pooled analysis (including the control group) yielded a mean (SE) value for compensation for carbon monoxide of $65 \cdot 4(3 \cdot 6) \%$ and for nicotine of $78 \cdot 8(4 \cdot 3) \%$ (the lower value of compensation for carbon monoxide than for nicotine reflects the fact that the proportional reduction in yield of low tar to high tar cigarettes is greater for carbon monoxide than for nicotine).

Subsidiary analyses to investigate whether individuals who dropped out of the study introduced any bias were carried out in the fast reduction group by comparing compensation at visit 3 in the 99 volunteers who completed all five visits with compensation over the same period in the 46 who did not. These analyses indicated that the effect of such biases was likely to be relatively small. Compensation for $\mathrm{COHb}$ in those who dropped out was $83.7 \%$ (95\% CI $65 \cdot 8 \%$ to $101 \cdot 6 \%$ ) compared with $65.9 \%(95 \%$ CI $55.2 \%$ to $76.5 \%)$ in those who did not, a difference that could have occurred by chance $(p=0 \cdot 2)$. Had the subsequent drop outs not been included at visit 3 , the effect of their exclusion would have been to alter the estimate of compensation at visit 3 from $68.3 \%$ to $65 \cdot 9 \%$. It seems reasonable to assume, therefore, that the estimates of compensation for carbon monoxide at later visits are only marginally affected by the drop outs. Compensation for nicotine in those who dropped out was $85 \cdot 7 \%(95 \%$ CI $63 \cdot 6 \%$ to $107 \cdot 8 \%)$ compared with $77 \cdot 1 \%$ (95\% CI $67 \cdot 9 \%$ to $86.3 \%$ ) in those who did not, again a difference that could have occurred by chance.

\section{Discussion}

Our results reinforce and extend previous work on compensatory smoking. The relative intake of tobacco smoke at the final visit compared with that before randomisation was in the range of 1.4-1.5 in both the fast reduction group and the slow reduction group whether estimated from $\mathrm{COHb}$ or cotinine as markers. By the end of the study participants were smoking cigarettes $40-50 \%$ "harder" than at the start of the study.

The estimate of compensation, using the intake of carbon monoxide and measurement of $\mathrm{COHb}$ levels, was $65 \%$; the estimate using nicotine and serum cotinine was $79 \%$. These values would be expected to be different for different smoke constituents because the proportional changes in their yields are different. While compensation for the tar could not be calculated directly, it can be estimated from the expectation that, for a particular brand change, relative intake for tar will be similar to that for nicotine and carbon monoxide. Using data from the fast reduction group, where relative intake for nicotine was 1.48 at visit 5 and average tar yield at visit 5 was $53 \%$ of its average value at visits 1 and 2 , an estimate of compensation for tar is $62 \%(0.62=-\log$ $(1.48) / \log (0.53)$ - equation 3 in Methods). The assumption that relative intake for tar is the same as that for nicotine is a reasonable one given the similarity in relative intake values at visit 5. If the relative intake for carbon monoxide $(1.46)$ is used, a similar compensation estimate of $60 \%$ is obtained.

These results for compensation can be applied to a particular brand change to illustrate the expected benefits of switching to a low tar cigarette. A typical change of brand might be from a cigarette yielding $16 \mathrm{mg}$ tar, $17 \mathrm{mg}$ carbon monoxide, and $1.5 \mathrm{mg}$ nicotine per cigarette to a cigarette yielding $8 \mathrm{mg} \operatorname{tar}(50 \%$ of initial value), $8 \mathrm{mg}$ carbon monoxide ( $47 \%$ ), and $0.8 \mathrm{mg}$ nicotine $(53 \%)$ per cigarette (a typical "low tar" cigarette in Britain). The corresponding reduction in intake would be $23 \%$ for tar, $23 \%$ for carbon monoxide, and $12 \%$ for nicotine. Table 3 shows predicted relative intakes and reductions in intake for a range of possible reductions in yield. The average tar yields when this study was carried out were $14-15 \mathrm{mg}$ per cigarette, higher than in $1993(11 \mathrm{mg})$. If our model of compensation is correct, our results should not be materially affected by the lower current yields. Current regulations limit tar yields to a maximum of $15 \mathrm{mg}$. This will fall to $12 \mathrm{mg}$ after $31 \mathrm{De}-$ cember 1997. 
Those who attended all five visits reduced the average number of cigarettes that they smoked over the course of the study to a small extent; $15 \%$ in the control group, $32 \%$ in the fast reduction group, and $28 \%$ in the gradual reduction group did not attend all five visits. Because the results depend on serum cotinine or $\mathrm{COHb}$ measurements, our conclusions must be based on an "on treatment" analysis of the results rather than on an "intention to treat" basis. The possibility that those who remained in the study, on average, inhaled differently from those who failed to attend cannot be completely excluded. Compensation for $\mathrm{COHb}$ in the fast reduction group in those who ceased to attend when estimated from their first three visits was higher (though not significantly so) than that for the rest of the study group, suggesting that our estimates of compensation may be too low.

There is no doubt that the best advice to smokers is to give up smoking altogether. The effect of switching to low tar cigarettes is small in comparison with giving up altogether, and much less than would be expected from a comparison of published tar yields. While our results indicate that switching to low tar cigarettes is likely to confer a health benefit in respect of at least some diseases associated with smoking, the effect will be modest compared with not smoking at all. If smokers cannot give up smoking then switching to cigarettes with a lower tar yield would be better than making no change at all.

We would like to acknowledge the help of Jane Stock, Ruth Morgan, Christine Cattini, Robert Barlow, and Raymond Cheng in the conduct of this trial, Robert Waller for supplying recent tar yield data, and Malcolm Law for his helpful critical comtar yield data, and Malcolm Law for his helpful critical com-
ments. We would like to thank all those British civil servants ments. We would like to thank all those British civil servants
who participated in the study. We thank the Tobacco Products Research Trust for their financial support.

1 International Agency for Research on Cancer. Monographs on the evaluation of the carcinogenic risk of chemicals to on the evaluation of the carcinogenic risk
humans. Tobacco Smoking 1986, No. 38.

humans. Tobacco Smoking 1986, No. 38 .
2 Wald N, Howard S. Smoking, carbon monoxide and arterial disease. Ann Occup Hyg 1975;18:1-14.

3 Benowitz NL, Kuyt F, Jacob P, Jones P, Osman A. Cotinine disposition and effects. Clin Pharmacol Ther 1983;34:60411 .

4 Knight GJ, Wylie P, Holman MS, Haddow JE. Improved 125-I radioimmunoassay for cotinine by selective removal of bridge antibodies. Clin Chem 1985;31:118-21.

5 Stephen A, Frost C, Thompson S, Wald NJ. Estimating the extent of compensatory smoking. In: Wald NJ, Froggatt P, eds. Nicotine, smoking and the
Oxford University Press, 1989.

6 Chiang AC. Fundamental methods of mathematical economics. 2nd edn. Tokyo: McGraw Hill Kogakusha, 1974. 